\title{
Experience of using clove oil for olfactory enrichment in Russian Zoos
}

\author{
T.A. Karmanova, D.D. Volgina, T.V. Antonenko*, A.V. Matsyura
}

\author{
Altai State University \\ Lenin St. 61, Barnaul, 656049, Russia \\ *E-mail: tv bio@mail.ru
}

Received: 14.08.2019. Accepted: 26.09.2019

\begin{abstract}
Successful experiments on olfactory enrichment of clove oil in Russian zoos have been carried out. Olfactory enrichment with clove oil reduced or eliminated stereotypical behavior (pacing) in most Amur tigers, African lions, and some Canadian and Red wolves. The behavior of the Far Eastern leopard and the Snow leopard behavior has not changed significantly under the influence of clove essential oil. Olfactory enrichment of clove essential oil is more successful for young animals.
\end{abstract}

Key words: Olfactory enrichment; Clove oil; Amur tiger; African lion; Far Eastern leopard; Snow leopard; Canadian wolf; Red wolf; zoo; Captivity

\section{Introduction}

Modern approaches to keeping animals in captivity require the creation of certain conditions that must meet the biological needs of wild species. The fundamental impossibility of completely reproducing natural conditions sets a difficult task of organizing a complex artificial environment in captivity. However, the lack of aviary space, stress, a high level of predictability of the environment, the absence of incentives that trigger certain behavioral mechanisms, and many other factors that are unavoidable under artificial conditions, lead to the emergence of various behavioral pathologies. Stereotypical behavior is the most common behavioral pathology. Increasing interest is emerging regarding the evaluation of currently used enrichment techniques that are alleged to reduce stereotypic behaviors (Swaisgood, Shepherdson, 2005; Antonenko, Medvedeva, Panchuk, 2017).

Environmental enrichment is the most common method to solve this problem. There are many different ways to improve welfare of captive animals. Success has been found in olfactory stimulation via the introduction of novel scents (Resende et al., 2011; Vidal et al., 2016; Antonenko, Ulitina, Pysarev, 2018). Single novel odorants recognition and noradrenergic mechanisms are crucial in mediating neural plasticity induced by olfactory enrichment (Veyrac et al., 2009).

The chief purpose of the investigation was to establish the effect of environmental enrichment with clove essential oil on the behavior of large predators in Russian zoos. The secondary aim is to estimate the time budget for males and females. The third object of the experiments is to identify pathological forms of behavior.

\section{Materials and Methods}

Our research took place at the «Leningrad Zoo» (Saint Petersburg), at the Barnaul zoo «Forest fairy tale» and in the Park of flora and fauna «Roy creek» (Krasnoyarsk). We tested Amur tigers (Panthera tigris altaica), African lions (Panthera leo leo), Far Eastern leopard (Panthera pardus orientalis), Snow leopard (Uncia uncia), Red wolfs (Cuon alpinus) and Canadian wolfs (Canis lupus pambasileus) available at this zoos (Table 1).

Table 1. Sex-age characteristics of the studied species.

\begin{tabular}{lllll}
\hline Species & Name & Sex & Age & Zoo \\
Amur tiger & Bagira & Female & 5 & Forest fairy tale (Barnaul) \\
Amur tiger & Sherhan & Male & 3 & Forest fairy tale (Barnaul) \\
Amur tiger & Gerda & Female & 16 & Leningrad Zoo (Saint Petersburg) \\
Amur tiger & Amadei & Male & 9 & Leningrad Zoo (Saint Petersburg) \\
African lion & Altai & Male & 4 & Forest fairy tale (Barnaul) \\
African lion & Taisya & Female & 6 & Leningrad Zoo (Saint Petersburg) \\
African lion & Adam & Male & 12 & Leningrad Zoo (Saint Petersburg) \\
Far Eastern leopard & Elisei & Male & 7 & Forest fairy tale (Barnaul) \\
Snow leopard & Dragon & Male & 14 & Roy creek (Krasnoyarsk) \\
Red wolf & Victoria & Female & 11 & Forest fairy tale (Barnaul) \\
Red wolf & Verona & Female & 2 & Roy creek (Krasnoyarsk) \\
Canadian wolf & Black & Male & 6 & Forest fairy tale (Barnaul) \\
Canadian wolf & Viola & Female & 10 & Roy creek (Krasnoyarsk) \\
\hline
\end{tabular}


Feeding of all animals is carried out according to the ration adopted in zoos. One "hungry" day is organized for all predators a week. All animals that were monitored were born in captivity and acquired in other zoos.

Cats behaviour are studied by continuous real-time measurement and "Ad Libitum" (Altmann, 1974).

Olfactory enrichment has been investigated with clove oil. The experiment consisted of background observation, enrichment and post-enrichment. As an indicator of the effectiveness of the experiment, the manifestation of stereotypical behavior on the day of background observations, on the day of enrichment and on the day after enrichment was analyzed.

\section{Results and Discussion}

In order to assess the well-being of the animal it is important to quantitate the time' budget and to analyze the causes of such pathological behaviors as movement stereotypes.

Table 2. Dynamics of pathological behavior in the enrichment of clove essential oil, (\%).

\begin{tabular}{lllll}
\hline Species & Name & Background observations & Enrichment & Post-enrichment \\
Amur tiger & Bagira & 13,11 & 0,00 & - \\
Amur tiger & Sherhan & 7,35 & 0,00 & - \\
Amur tiger & Gerda & 1,22 & 0,00 & 1,70 \\
Amur tiger & Amadei & 0,13 & 1,79 & 0,00 \\
African lion & Altai & 53,3 & 45,6 & 27,8 \\
African lion & Adam & 17,9 & 0,00 & 3,6 \\
African lion & Taisya & 25,0 & 0,00 & 14,0 \\
Far Eastern leopard & Elisei & 9,4 & 8,4 & 8,6 \\
Snow leopard & Dragon & 74,1 & 83,1 & 77,3 \\
Red wolf & Victoria & 6,17 & 3,61 & 6,25 \\
Red wolf & Verona & 5,29 & 0,99 & 0,0 \\
Canadian wolf & Black & 14,81 & 12,04 & 13,5 \\
Canadian wolf & Viola & 0,81 & 0,00 & 0,00 \\
\hline
\end{tabular}

One of the main indicators of the success of the environmental enrichment is the reduction in the proportion of pathological forms of behavior in the animal's time budget. After sensory enrichment with the cinnamon essential oil, the male lion from the Barnaul zoo experienced a reduction in the proportion of pathological behavior by almost half (to $27 \%$ ) in the post-enrichment period compared with background observations. During the period of enrichment, the lions from the Leningrad zoo managed to completely eliminate movement stereotypes (Table 2). This can be traced and in the female of the red wolf from the Barnaul zoo during the enrichment period, it was possible to reduce the stereotype share by almost 2 times (to 3.6\%). The female red wolf of the Krasnoyarsk zoo managed to completely eliminate stereotypical behavior. A female tiger from the Barnaul zoo with olfactory enrichment did not show stereotypical behavior on the day of enrichment. Also on the day of enrichment, the pathological form of behavior was eliminated from a male Amur tiger in this zoo (Table 2). Olfactory enrichment with clove oil caused different dynamics of stereotypical behavior in tigers from the Leningrad Zoo. Stereotypic movements were recorded in the female on the day of background observations (1.22\%) and on the day of post-enrichment $(1.70 \%)$. Pacing was absent on the day of sensory enrichment. Stereotype was recorded on the day of baseline observations $(0.13 \%)$ and on the day of enrichment (1.79\%) in the male. On the day of post-enrichment, it showed no stereotyped movements. The male had a previous negative experience of unsuccessful enrichment and neophobia before new types of enrichment.

The stereotypical behavior in the Far Eastern leopard could not be eliminated. It changed unreliable on the day of the experiment and on the day of post-enrichment (Table 2). Olfactory enrichment with clove oil increased the duration of the manifestation of pathological forms of behavior in the Snow leopard (background - 74.1\%, enrichment - 83.1\%, post-enrichment - 77.3\%). The sharp increase in the indicator may be due to the novelty smell for the animal and the increased unpredictability of the environment.

\section{Conclusion}

Olfactory enrichment with clove oil reduced or eliminated stereotypical behavior (pacing) in most Amur tigers, lions, and some wolves. The behavior of the Far Eastern leopard and the Snow leopard behavior has not changed significantly under the influence of clove essential oil. Olfactory enrichment of clove essential oil is more successful for young animals.

Based on the obtained results, we can conclude that the use of odor environmental enrichment can significantly reduce the proportion of pathological forms of behavior (pacing) in zoos. This helps to improve the welfare of captive animals, which is extremely necessary to take into account when keeping and breeding rare and endangered species of animals.

\section{References}

Altmann, J. (1974). Observational study of behavior, sampling methods. Behaviour, 49, pp 227-267.

Antonenko, T.V., Panchuk, K.A., Medvedeva, Yu.E. (2017). The influence of olfactory enrichment on the welfare of large felines in captivity. Ukrainian Journal of Ecology, 7(4), 134-138, doi: 10.15421/2017_105.

Antonenko, T.V., Ulitina, O.M., Pysarev, S.V. (2018). Welfare of Eurasian Iynx in the Barnaul Zoo. Ukrainian Journal of Ecology, 2, 15 . 
Resende, L.S., Pedretti Gomes, K. C., Andriolo, A., Genaro, G., Remy, G. L., Almeida Ramos Júnior, V. (2011). Influence of cinnamon and catnip on the stereotypical pacing of oncilla cats (Leopardus tigrinus) in captivity. Journal of Applied Animal Welfare Science, 14(3), 247-254. https://doi.org/10.1080/10888705.2011.576981.

Swaisgood, R., Shepherdson, D. (2005). Scientific approaches to enrichment and stereotypies in zoo animals: what's been done and where should we go next? Zoo Biology, 24(6), 499-518.

Veyrac, A., Sacquet, J., Nguyen, V., Marien, M., Jourdan, F., Didier, A. (2009). Novelty determines the effects of olfactory enrichment on memory and neurogenesis through noradrenergic mechanisms. Neuropsychopharmacology, 34, 786-795; doi:10.1038/npp.2008.191.

Vidal, L. S., Guilherme, F. R., Silva, V. F., Faccio, M. C. S. R., Martins, M. M., Briani, D. C. (2016). The effect of visitor number and spice provisioning in pacing expression by jaguars evaluated through a case study. Braz. J. Biol, 76(2), São Carlos Apr./June 2016 Epub Mar 08, 2016.

Citation:

T.A. Karmanova, D.D. Volgina, T.V. Antonenko, A.V. Matsyura (2019). Experience of using clove oil for olfactory enrichment in russian zoos. Ukrainian Journal of Ecology, 9(3), 381-383.

(cc) $\mathrm{EY}$ This work is licensed under a Creative Commons Attribution 4.0. License 